\title{
A sociologia da educação de Bourdieu na revista Actes de la Recherche en Sciences Sociales
}

\author{
Ana Paula Hey* , Afrânio Mendes Catani* e \\ Cristina Carta Cardoso de Medeiros**
}

La sociologie de l'éducation est un chapitre, et non des moindres, de la sociologie de la connaissance et aussi de la sociologie du pouvoir [...]. Loin d'être cette sorte de science appliquée, donc inférieure et bonne seulement pour les pédagogues [...], elle se situe au fondement d'une anthropologie générale du pouvoir et de la légitimitél. PIERRE BOURDIEU, La noblesse d'État, 1989, p. 13.

O presente artigo dedica-se ao esquadrinhamento das teses centrais desenvolvidas por Pierre Bourdieu (1930-2002) relativas à educação, tendo como núcleo irradiador a criação da revista Actes de la Recherche en Sciences Sociales (ARSS). O sociólogo era um acadêmico renomado quando, com 45 anos incompletos, criou o periódico, cujo primeiro número circulou em janeiro de 1975. Ele o dirigiu até falecer, publicando ali quase uma centena de artigos, cuja amplitude temática e empírica reflete a composição profícua de seu "esporte de combate".

$\mathrm{Na}$ França dos anos de $1960^{2}$ as questões de educação não se constituíam em objeto científico e a 'nascente' sociologia da educação vai contribuir para legitimá-las

* Universidade de São Paulo - UsP.

** Universidade Federal do Paraná - UfPR.

1. A sociologia da educação é um capítulo, e não dos menores, da sociologia do conhecimento e, também, da sociologia do poder [...]. Longe de ser esta espécie de ciência aplicada, portanto inferior e adequada apenas para os pedagogos [...], ela se situa no fundamento de uma antropologia geral do poder e da legitimidade" (tradução nossa).

2. Vale lembrar que, nesse período e em grande parte dos países desenvolvidos, as análises sociológicas da educação legitimam-se com base em impulso heterônomo ao próprio campo disciplinar, motivadas pela aceitação ou rechaço das teses de mobilidade social e dos processos de democratização que colocavam a escolarização no centro do debate social e político. 
no campo da sociologia. A peculiaridade desse novo espaço de produção acadêmica reside no fato de ser ocupado por recém-chegados a esse domínio - casos de Bourdieu, Passeron, Boudon -, dotados de forte capital científico gerado em disciplinas dominantes (como a filosofia) e egressos da prestigiosa École Normale Supérieure (Poupeau, 2003), colaborando para dinamizar a sociologia do período, mas também tornando a educação um de seus objetos centrais. Assim, estas páginas buscam retratar a contribuição do autor à sociologia da educação, o qual já enfatizava, nos anos de 1960 e 1970, a reflexão na constituição do capital cultural e na cultura, sobretudo escolar, e em sua consequente apropriação e distribuição desigual entre as classes.

O próprio Bourdieu afirma:

[... a sociologia da educação e da cultura desempenhou um papel importante em meu trabalho, na medida em que o sistema escolar era uma ocasião privilegiada de estudar os fenômenos de transmissão cultural ou, em outras palavras, de colocar a respeito de nossa sociedade problemas que os antropólogos tradicionalmente colocam acerca das sociedades estudadas por eles, como por exemplo, o problema da transmissão das estruturas mentais e do sistema de classificação (2000, pp. 18-19).

Em seu artigo de 1971, "Reprodução cultural e reprodução social”, estabelece as bases do que seria a sua sociologia da educação, cuja análise repousa na confluência entre a estrutura de reprodução das relações de força e das relações simbólicas entre as classes e a reprodução da estrutura de distribuição diferenciada do capital cultural entre as classes, apontando os mecanismos pelos quais o sistema de ensino contribui para a manutenção desse "círculo" (Bourdieu, 1974). Nas páginas da ARSS reforçam-se essas primeiras formulações sistemáticas acerca das desigualdades sociais por meio da cultura, além do entendimento de que o sistema escolar engendra um modo de dominação específico, contribuindo assim nos processos de reprodução social.

A ARSS foi concebida no então criado Centre de Sociologie de l'Éducation et de la Culture, dirigido por Bourdieu, pertencente à École des Hautes Études en Sciences Sociales (EHESs) 3 e associado ao Centre National de la Recherche Scientifique (CNRS). O laboratório surgiu em 1970 com a cisão do Centre de Sociologie Européenne, fundado por Raymond Aron em 1959, do qual Bourdieu tinha sido o secretário geral desde 1962. O lançamento da publicação continha como principal objetivo, conforme revelado na apresentação não assinada, mas escrita por Bourdieu, romper com o padrão seguido pelas demais revistas acadêmicas, possibilitando uma abertura para o atelier do pesquisador. Tratava-se de dar ferramentas para o rompi-

3. A eness foi criada em 1975 com base na sexta seção da École Pratique des Hautes Études, de 1947. 
mento da crença no senso comum, rescindindo igualmente com os formalismos da publicação científica, expressando uma tomada de posição drástica:

O real acesso ao conhecimento dos objetos que são os mais frequentemente investidos de todos os valores do sagrado como condição de liberar as armas do sacrilégio só ocorre se se acreditar na força intrínseca da ideia verdadeira; o charme da crença só pode ser rompido opondo-se a violência simbólica à violência simbólica e fornecendo, quando necessário, as armas da polêmica a serviço das verdades conquistadas pela polêmica da razão científica (Bourdieu, 1975, p. 3).

O periódico, transdisciplinar, esforçou-se para "desnacionalizar a ciência social” e inovar na representação gráfica e nos resultados da pesquisa. Para Miceli (2002), a revista procurou dar conta de um tríplice desafio: "afirmar um rosto teórico original para o ofício de sociólogo, lançar as bases de alianças com cientistas sociais estrangeiros considerados pares [...] e testar os graus de universalização dos achados e dos conceitos derivados dos seus experimentos de investigação”.

A intenção de Bourdieu ao criar a ARSS era romper com o 'marasmo' acadêmico reinante na produção científica de então. Ele entendia que pouco havia mudado nesse domínio com relação ao início dos anos de 1960 na França, em que as revistas existentes (Revue Française de Sociologie, Les Cahiers Internationaux de Sociologie, Archives Européennes de Sociologie, Sociologie du Travail e Études Rurales) não motivavam o debate em torno da sociologia que se praticava (Bourdieu, 2005, p. 62).

É oportuno lembrar, aqui, a empreitada de Durkheim ao fundar a revista L'Année Sociologique, em 1896/1897, que se constituiu na primeira e mais antiga das revistas científicas próprias das ciências sociais ${ }^{4}$, uma verdadeira demarcação da disciplina nascente em relação às então dominantes. No prefácio a seu número inicial, Durkheim redigiu uma espécie de manifesto programático da disciplina, além das 50 páginas dedicadas à sociologia geral, "c ' est-à-dire à tout la sociologie d 'hier" 5 (Simiand, 1987, p. 4) e de outras 400 de análise sociológica com base em materiais empíricos diversos, versando sobre a história das religiões, a história dos fatos morais da civilização, o direito, a criminologia, a economia. Vale ressaltar ainda a importância assumida, nos dias que correm, das publicações via revistas científicas no âmbito dos jogos referentes à produção e à circulação científica, em que grande parte das guerras palacianas do mundo científico podem ser observadas (ARSS, 2004/2005, 2006, 2009).

\footnotetext{
4. O primeiro número de L'Année Sociologique (1898), dirigida por Durkheim, então professor em Bordeaux, contou com a colaboração de Simmel, Richard, Lévy, Bouglé, Fauconnet, Hubert, Lapie, Mauss, Milhaud, Muffang, Parodi, Simiand. Ver Simiand ([1898] 1987) e Karady (1988).

5. Tradução nossa: "isto é, à toda sociologia do passado".
} 
Para Wacquant ${ }^{6}$, a ARSS, de maneira distinta de Esprit e Les Temps Modernes,

É mais uma revista cientifica que intelectual, de maneira que a validade metodológica e a adequação empírica têm prioridade sobre a elegância literária e a retidão política. Em contraste com L'Homme ou Annales: économies, societés, civilisations, entretanto, é obstinadamente transdisciplinar, e atenta aos temas sociopolíticos da atualidade: é o órgão de uma ciência da sociedade militante cujo público é basicamente, embora não exclusivamente, composto por intelectuais (2002, p. 105, grifos no original).

Ao contrário das publicações de seu tempo, a ARSS, um verdadeiro 'laboratório-em-ação sociológico, procurou "desmascarar as formas sociais e os formalismos" pelos quais a realidade dissimula a si mesma (Wacquant, 2002, p. 105), acabando por multiplicar as experiências formais e as inovações estilísticas em duas dimensões. Em primeiro lugar, não se publicam apenas artigos acadêmicos padrão, mas também

[...] resenhas curtas, peças polêmicas, notas de leitura, documentos inéditos e relatórios de campo ou experimentos rigorosamente editados, auto-reflexivos [...]. Em segundo lugar, o artigo arquetípico dos Actes tece o texto com fotografias, fac-similes de exposições e excertos de entrevistas ou dados crus de observações em caixas e barras laterais dispostas ao longo do texto. A revista utiliza também diferentes tipos e fontes e mistura estilos diretos e indiretos, tudo em um esforço para uma precisão analítica com acuidade experimental (Idem, 2002, p. 105).

A publicação, hoje trimestral, divulgou, além de temáticas que perpassavam o tecido social, artigos dedicados à economia dos bens culturais (pintura, livros, literatura, moda, música, museus, academia, mito, ciência e as respectivas inter-relações), à lógica da classificação social e à fabricação de coletivos sociais; textos referentes à etnicidade, à região, à nação, à vida social, envolvendo a família, a empresa, o partido, o Estado. A esse inventário de assuntos podem-se acrescentar estudos das estratégias sociais de dominação, distinção e reprodução, bem como aqueles relativos às práticas e aos poderes intelectuais, além de números sobre as novas formas de desigualdade social e marginalidade originadas nos anos de 1990 (Wacquant, 2002, pp. 105-106). Através da ARSS, Bourdieu manteve profícuo diálogo com renomados intelectuais estrangeiros - Howard Becker, Aaron Cicourel, Robert Darnton, Norbert Elias,

6. Essa afirmação de Wacquant acerca da ARss integra o trabalho de consagração por ele realizado e por muitos daqueles que trabalharam com o autor. Para nós, a importância da revista no âmbito das Ciências Sociais reside em como Bourdieu a utilizou como mecanismo de divulgação de sua expedição sociológica vinculado a um programa de investigação de caráter universal. Após sua morte, o jogo da preparação dos dossiês rompe com essa dinâmica. 
Erving Goffman, Eric Hobsbawm, Carlo Ginzburg, Gershon Scholen, Joan Scott, Carl Schorske, Paul Willis, Raymond Williams etc. Grande quantidade de colaboradores franceses também frequentaram as páginas da revista: Robert Castel, Luc Boltanski, Abdelmalek Sayad, Patrick Champagne, Jean-Claude Chamboredon, Yvette Delsaut, Monique de Saint Martin, Remi Lenoir, Louis Pinto, Gisèle Sapiro, Michael Pollack, Roger Chartier, Nathalie Heinich, Christophe Charle, Jean Bollack, Louis Marin, Jacques Bouveresse, Robert Linhart, Bruno Latour.

As atividades editoriais do sociólogo haviam se iniciado nos anos de 1960, com a coleção Le Sens Commun, nas Éditions de Minuit, que dirigiu por quase trinta anos. Após a ARSS, tal empreendimento estendeu-se com a criação, em 1989, da Liber: Revista Européia de Livros (depois, com o subtítulo Revista Internacional de Livros), veículo trimestral, encartado na própria Actes e também publicado sob a forma de suplemento em jornais de grande circulação ${ }^{7}$. A Liber abriu-se para autores de vários países, englobando aqueles que pertenciam a centros de produção intelectual situados mais à margem. Tendo durado até 1998, era publicada em francês, alemão e italiano, contando com versões em búlgaro, húngaro, sueco, romeno, grego, norueguês e turco.

Em 1995, além de integrar o Parlamento Internacional dos Escritores e o Comitê Internacional de Apoio aos Intelectuais Argelinos, Bourdieu criou a editora Liber-Raisons d'Agir, depois apenas Raisons d'Agir (após sua morte seu filho, Jérôme Bourdieu, passou a dirigir a editora), publicando pequenos livros densos, bem documentados e baratos sobre problemas políticos e sociais da atualidade, escritos por sociólogos, historiadores, economistas, escritores e artistas, que possuíam "a vontade militante de difundir o saber indispensável à reflexão e à ação política em uma democracia” (Wacquant, 2002, p. 100). Sua intenção era a de constituir uma espécie de "enciclopédia popular internacional". A maioria desses livros foi publicada em reação ao cerceamento da mídia e do mercado editorial, que se recusavam a discutir, aprofundar e editar temas que, se escamoteados, continuariam a contribuir para a manutenção do que o autor definiu como sendo "os fundamentos ocultos da dominação".

Em seu número inaugural, a ARSS continha um "manifesto reivindicando, explicitamente, o direito de publicar textos não definitivos". Nessa sistemática adotada, explica Bourdieu em entrevista, "as retomadas dos artigos em livros não são simplesmente patchworks". Na maioria das vezes, foram trabalhos planejados que desenvolveu por etapas, produzindo "peças pensadas como elementos de um conjunto $[. .$.$] . Por esse procedimento chega-se a fazer construções de uma coerência$

7. Em três jornais diários (Le Monde, França; El País, Espanha; Frankfurter Allgemeine Zeitung, Alemanha) e em outras duas publicações especializadas (Indice, Itália e Times Literary Supplement, Inglaterra), ver Ferenczi (2004). No Brasil, Sergio Miceli foi o responsável pela seleção e organização de uma coletânea de artigos publicados na Liber (Edusp, 1997). 
e de uma complexidade impossíveis de alcançar pela simples redação de um plano linear" (Bourdieu e Delsaut, 2005, pp. 186-188).

Parte significativa da produção do autor encontrada na revista ARSS, em forma de rascunho, serviu como ensaio à maioria dos trabalhos que resultaram em seus livros (Idem, 2005, p. 187). O mapeamento ${ }^{8}$ dos 11 artigos ali publicados - arrolados no final deste texto - insere o pensamento de Bourdieu acerca da temática educacional ${ }^{9}$ em um movimento contínuo, inscrevendo-a em sua trajetória intelectual.

\section{A educação como objeto sociológico de Bourdieu na ARSS}

A educação aparece como objeto na ARSS desde seu primeiro número, na sessão intitulada 'Estudo comparado dos modos de dominação', cujos autores Francine Muel e Claude Grignon apresentaram, respectivamente, os artigos " $L$ 'école obligatoire et l'invention de l'enfance anormale" (A escola obrigatória e a invenção da infância anormal, 1975, pp. 60-74) e "L'enseignement agricole et la domination symbolique de la paysannerie" (O ensino agrícola e a dominação simbólica dos agricultores, 1975, pp. 75-92).

No número $2 \mathrm{da}$ ARSS aparece pela primeira vez um artigo de Bourdieu e Luc Boltanski, "Le titre et le poste: rapports entre le système de production et le systéme de reproduction" (O diploma e o cargo: relações entre o sistema de produção e o sistema de reprodução $\left.{ }^{10}\right)$. Nele se enfatiza a análise da relação entre o aparelho econômico e o sistema de ensino, ressaltando-se a necessidade de distinguir a dinâmica própria da economia - responsável pelas mudanças da estrutura de cargos - e o sistema de ensino, produtor das capacidades técnicas dos produtores e dos diplomas de que são portadores (1975, p. 98). Evidencia-se a questão da mobilidade social, demonstrando-se ser ela reduzida à mobilidade individual, uma vez que é produto da transformação das relações entre o aparelho de produção dos agentes (sistema escolar) e da mudança do aparelho econômico, entre a defasagem do habitus e as estruturas. $\mathrm{O}$ artigo terá prolongamento em "Classement, déclassement, reclassement" (1978), publicado na ARSS, comentado nas páginas seguintes, e integrando o segundo capítulo de La distinction (1979).

8. Tal levantamento foi trabalhado preliminarmente em Medeiros (2007 e 2013).

9. Fazem parte dessa preocupação os livros Les héritiers (1964), La reproduction (1970), Homo academicus (1984) e La noblesse d'État (1989). Ademais, os artigos de "A economia das trocas simbólicas" (1974) demonstram a gênese da interpretação sistemática do autor nesse domínio: "Sistemas de Ensino e Sistemas de Pensamento" (1967); "A Excelência e os Valores do Sistema de Ensino Francês" (1970); "Reprodução Cultural e Reprodução Social” (1971).

10. Traduzido em Nogueira e Catani (orgs.) (1998, pp. 127-144). 
Em "Le titre et le poste" pode-se observar a existência de uma defasagem entre a estrutura das profissões e a produção de produtores pelo sistema escolar, ocasionando "desajuste" com relação às demandas do mercado de trabalho, possibilitando o que Bourdieu chamaria de "inflação de diplomas". Nogueira e Catani (1998, p. 12) escrevem que anos depois, no livro Homo academicus (1984), Bourdieu se mostrará hesitante quanto ao emprego da analogia da inflação, "à qual recorri em fase anterior de meu trabalho", uma vez que certas estratégias individuais ou coletivas dos agentes, como, por exemplo, a criação de novos mercados e profissões, podem proteger portadores de certificados escolares desvalorizados (Bourdieu, 1984, p. 214).

Ainda em 1975, no terceiro número da ARSS, registra-se o artigo "Les catégories de l'entendement professoral" (As categorias do juízo professoral ${ }^{11}$ ), escrito com Monique de Saint Martin. Com base em material empírico composto por 154 fichas de avaliação de alunas de um curso preparatório à École Normale Supérieure de Paris, nos anos de 1960, que fornecem informações sobre cada estudante, a profissão e o endereço dos pais, bem como notas de tarefas escolares e apreciações de intervenções orais, suas reflexões se dedicam às formas de classificação e às funções sociais deste sistema classificatório, produzidas cotidianamente pelos professores de maneira dissimulada e distante da intenção pedagógica.

Ambos constatam que os julgamentos mais favoráveis e as notas vão se elevando na medida em que a posição social da aluna se eleva - embora percebam que o primeiro elemento esteja mais fortemente correlacionado à origem social do que a nota. Entendem, ainda, ser bem mais relevante a demonstração que

\footnotetext{
Nada escapa ao julgamento operado pelo docente na hora de avaliar o produto do trabalho discente [...]. Para além dos "critérios internos" de avaliação de um determinado tipo de conhecimento (domínio do campo, vocabulário técnico, entre outros), levam-se em conta, sobretudo, "critérios externos" tais como postura corporal, maneiras, aparência física, dicção, sotaque, estilo da linguagem oral e escrita, cultura geral etc. (Nogueira e Catani, 1998, pp. 12-13).
}

Serão analisadas, assim, as formas escolares de classificação que, a exemplo das "formas primitivas de classificação" das quais falavam Durkheim e Mauss, transmitem-se essencialmente na e pela prática, externa a qualquer intenção pedagógica (Bourdieu e Saint Martin, 1975, p. 69). Destacam os efeitos lógicos inseparáveis dos efeitos políticos, considerando a taxionomia escolar pela qual o sistema de classificação expressa ideologia em estado prático, uma vez que guarda relação com a definição explícita de excelência, valendo-se de predicados daqueles que são socialmente do-

11. Traduzido em Nogueira e Catani (orgs.) (1998, pp. 185-216). 
minantes. Tal taxionomia explicita qualidades positivas (elegância, brilho, fineza, graça, dom, desenvoltura, originalidade, distinção, espontaneidade) e predicados que quase atingem as raias da negatividade ou, em muitos casos, atingem mesmo: esforço, modéstia, lisura, precisão, correção, pueril, vulgar, mal feito, pesado, estreito, desajeitado, medíocre.

Sob uma aparente neutralidade, o sistema de ensino se converte em uma máquina classificatória, consagrando a ordem social, enquanto os professores, autoridades delegadas desse sistema, exercem o julgamento dos alunos. A taxionomia escolar interpõe-se entre o indivíduo e sua trajetória, pronunciando o veredicto escolar. Realizando um paralelo, por meio de um trecho da aula de Bourdieu no Collège de France, podemos caracterizar a força desse veredicto no destino de um aluno:

\footnotetext{
Sem chegar a dizer, como Durkheim, que “a sociedade é Deus", eu diria: Deus não é nada mais do que a sociedade. O que se espera de Deus somente se consegue obter da sociedade, da contingência [...]. O juízo dos outros é o juízo final; e a exclusão social é a forma concreta do inferno e da danação. É também porque o homem é um Deus para o homem que o homem é um lobo para o homem (Bourdieu, 1982, p. 33).
}

"Classement, déclassement, reclassement" (Classificação, desclassificação e reclassificação ${ }^{12}$ ), de Bourdieu (1978), saiu no volume Le déclassement (A desclassificação) e aborda as transformações das relações entre as distintas classes sociais e o sistema de ensino. Como exposto antes, o artigo transformou-se em parte do capítulo 2, "L'espace social et ses transformations", de La distinction.

Bourdieu retoma parte da argumentação desenvolvida em "Le titre et le poste", apontando as alterações na estrutura social advindas da modificação de relações que se estabelecem entre os diplomas e os cargos como sequela de uma intensificação da concorrência pelos títulos escolares, desencadeada por classes e frações de classe dominantes, com o intuito de assegurar sua reprodução. $\mathrm{O}$ ingresso de frações de classe que até então não tinham acesso à escola, na disputa pelos títulos escolares, obrigou as frações cuja reprodução se garantia primordialmente pela escola a intensificar seus investimentos para manter a distinção de seus diplomas. De acordo com a posição que ocupam no espaço social, os diferentes grupos vão travar em torno do diploma verdadeira luta por sua classificação para não se desclassificarem ou para se reclassificarem, pois com o mesmo nível de diploma assumem-se postos gradativamente menos elevados na hierarquia ocupacional. 
Os detentores de capital social herdado, graças a uma origem social elevada, resistem à desvalorização dos diplomas, sendo o grau de resistência proporcional à posição que cada jovem ocupa na hierarquia dos diplomas. Valem-se de várias estratégias para assegurar a posição que lhes era garantida em época anterior, com o mesmo título. As grandes vítimas dessa desvalorização são os ingressantes no mercado de trabalho sem diplomas e, também, privados de capital social.

Na revista número 30 (1979), L'Institution Scolaire (A Instituição Escolar), encontra-se o artigo, "Les trois états du capital culturel" (Os três estados do capital cultural $\left.{ }^{13}\right)$. Centrando-se na exposição de capital cultural, escreve que essa noção:

[...] impôs-se, primeiramente, como uma hipótese indispensável para dar conta da desigualdade de desempenho escolar de crianças provenientes das diferentes classes sociais, relacionando o 'sucesso escolar', ou seja, os benefícios específicos que as crianças das diferentes classes e frações de classe podem obter no mercado escolar, à distribuição do capital cultural entre as classes e frações de classe (1979, p. 3).

Acrescenta que tal ponto de partida significa "uma ruptura com os pressupostos inerentes tanto à visão comum, que considera o sucesso ou o fracasso escolar como efeito das 'aptidões' naturais, quanto às teorias de 'capital humano'” (1979, p. 3). Entende que o capital cultural possui relação de homologia com o capital econômico, permitindo a seu possuidor a obtenção de vantagens ou lucros sociais. Ele se materializa em três formas: no estado objetivado, sob a forma da detenção de bens culturais (quadros, livros, dicionários, máquinas, instrumentos, monumentos), transmissíveis, como dinheiro, de maneira quase instantânea no que se refere à propriedade jurídica. A segunda no estado institucionalizado, consolidado em títulos, diplomas, certificados escolares, que agem como atestados de formação cultural. Da mesma maneira que o dinheiro possui relativa independência em relação ao portador do título:

Produto da conversão de capital econômico em capital cultural, estabelece o valor, no plano do capital cultural, do detentor de determinado diploma em relação aos outros detentores de diplomas e, inseparavelmente, o valor em dinheiro pelo qual pode ser trocado no mercado de trabalho - o investimento escolar só tem sentido se um mínimo de reversibilidade da conversão que ele implica for objetivamente garantido (1979, p. 6).

O capital cultural se apresenta, também, em estado incorporado, como cultura internalizada, sob a forma de disposições duráveis do organismo, um habitus,

13. Traduzido em Nogueira e Catani (orgs.) (1998, pp. 71-79). 
pressupondo longo trabalho de inculcação e assimilação, que deve ser investido pessoalmente pelo interessado - "tal como o bronzeamento, essa incorporação não pode efetuar-se por procuração" (1979, p. 4, grifos do original).

Em 1981, o tema das Grandes e Pequenas Escolas (Grandes et Petites Écoles ${ }^{14}$ ), desenvolvido em três longos artigos na ARSS, aparece no texto de Bourdieu, "Épreuve scolaire et consécration sociale: les classes préparatoires aux Grandes Écoles" (Prova escolar e consagração social: as classes preparatórias às Grandes Escolas), escrito com base em pesquisas que realizou com Yvette Delsaut e Monique de Saint Martin, focando no estudo das escolas de elite francesas, universo das formas possíveis de formação e consagração daqueles destinados a ingressar/permanecer nas posições dominantes, das quais a maioria já é proveniente. A análise centra-se nas classes preparatórias, encarregadas da preparação dos alunos ao concurso a uma Grande École (GE), tratadas como instituições dominadas pela lógica do concurso para alunos integráveis, expressa na imposição da organização do trabalho escolar, controle do tempo, prescrição das disciplinas escolares e incitação à competição.

As características objetivas dessas instituições escolares e das disposições socialmente constitutivas dos seus agentes permitem avaliar a mágica social da consagração, que ocorre mais fortemente quando o candidato estiver predisposto a reconhecê-la e a se submeter a seus princípios tácitos. A análise das escolas preparatórias às GE desenvolve-se com base em várias fontes, demonstrando o longo processo de objetivação pretendido com a pesquisa. Em 1968 aplicaram-se questionários aos alunos dessas classes, sendo 330 de turmas de premiére supérieure (Khâgne ${ }^{15}$ ) de liceus de algumas cidades da França (Paris, Brest, Clermont-Ferrand, Lille, Lyon, Toulouse) e 880 questionários aplicados aos alunos das classes de Matemática Especial (Taupe ${ }^{16}$ ), também distribuídos pelo país (Paris, Neully-sur-Seine, Clermont-Ferrand, Lille, Lyon, Toulouse e Versailles). Foram utilizadas duas pesquisas anteriores com 6 mil alunos em ciências e 2.300 em ciências humanas (lettres), além de se entrevistarem quarenta alunos e outros 160 professores de Paris e do interior; houve, ainda, o recurso a informantes (diretores, antigos professores e alunos), ao mapeamento de documen-

14. No sistema de ensino superior francês há uma nítida separação entre as Grandes Écoles, criadas na tradição universitária do Ancien Régime, mas compondo as instituições da Revolução, e as Universidades, mais novas, receptoras das massas e hierarquicamente menos prestigiosas.

15. Khâgnes (primeiro ano superior): "nos liceus, classes superiores de letras que operam também como cursos preparatórios para as Escolas Normais (Ulm, Sèvres) nas áreas humanísticas de letras e filosofia, nos quais são recrutados os professores do ensino superior, os pesquisadores e demais intelectuais de maior prestígio no campo intelectual francês; por extensão, os alunos dessas classes". Seus alunos são chamados de khâgneux. Nota de Sergio Miceli para a tradução brasileira de Bourdieu (2005, p. 41).

16. Taupes: classes de matemáticas especiais que preparam para o ingresso nas grandes escolas e na Escola Politécnica; seus alunos são chamados de taupins. 
tos relativos ao aspecto mais ritualizado da vida nas classes preparatórias (boletins, comunicados), além do recenseamento das expressões da experiência mais íntima dos efeitos produzidos pelo processo de consagração e de produção da crença (1981, p. 6).

O texto é ricamente ilustrado com resultados das análises e o relato das percepções das experiências de alunos e professores dessas instituições. Procurando romper com as evidências e se afastar da familiaridade, reflete sobre os efeitos da seleção e da transformação durável e profunda da consagração escolar como garantia de disposições cultivadas, identificando, assim, os fundamentos dessas classes dominadas pela lógica dos concursos de admissão.

O que distingue as classes preparatórias das outras instituições de ensino superior [...] é o sistema dos meios institucionais de iniciação, constrangimentos e controles que são acionados para reduzir toda a existência daqueles que se chamam ainda, aqui, de alunos (em oposição aos estudantes) a uma sucessão ininterrupta de atividades escolares intensivas, rigorosamente regradas e controladas tanto em seu momento quanto em seu ritmo (1981, p. 7).

Do ponto de vista do efeito pedagógico, o valor recai na maneira como se ensina e não no que é ensinado em si; o essencial do que é transmitido se situa não no conteúdo aparente, programas e cursos, mas na organização da ação pedagógica. Tal ação é mais sentida pelos alunos pelo fato de muitos deles se encontrarem em regime de internato, devendo sua força se desenvolver sob um silêncio essencial, visto como necessário, e fadado a escapar das discussões e da consciência críticas.

O domínio do tempo para garantir a produtividade, bem elevada nessas classes preparatórias, pressupõe um conjunto de condições institucionais, tais como a imposição de disciplinas e controles escolares, e o acionamento de um sistema de incitação destinado a encorajar a competição no interior de um grupo de colegas (1981, p. 10). O efeito do enquadramento total das classes preparatórias expressa-se no rendimento máximo, garantido pela presença obrigatória, pelo papel dos professores no controle e pela determinação da quantidade elevada de trabalhos e exercícios, nos concursos relâmpagos, na proclamação pública de notas e de classificações, entre outros. Através desses mecanismos impõe-se uma relação instrumental e pragmática com o trabalho intelectual (1981, p. 11).

Invocando a análise de Durkheim acerca do ensino jesuíta como infligindo uma cultura intensiva e forçada, afirma que esses adolescentes, isolados durante três ou quatro anos em um universo protegido e dispensado de toda preocupação material, sabem sobre o mundo apenas o que aprendem em trechos escolhidos de livros, nas questões de curso e de concurso, sendo o trabalho de inculcação da classe preparatória concebido para produzir "inteligências forçadas” (1981, p. 12). 
Em relação aos professores das classes preparatórias, “o corpo de treinadores”, por serem recrutados entre a elite dos professores de liceu (ensino médio), assumem papel totalmente dedicado à função professoral. O desempenho da sua ação pedagógica centra-se na repetição para instruir a respeito da organização do exercício e do enquadramento do trabalho de aprendizagem, secundarizando-se a transmissão do saber. Os professores encontram-se no centro dos mecanismos de reprodução do sistema do qual são os produtos; são emanados pela lógica de um sistema completo voltado para o concurso e, dispondo das condições favoráveis para um treinamento intensivo, inculcam certo tipo de cultura e de relação com a cultura com base em técnicas de retórica e de exposição dos conteúdos, em detrimento da reflexão, da pesquisa e do espírito inventivo de apropriação do conhecimento (1981, p. 14).

Quanto às características mais significativas das escolas de elite (Classes Preparatórias das GE e as GE, elas mesmas), Bourdieu assevera que elas só podem ser plenamente compreendidas com a condição de perceber sua função de consagração (ou de sociodicéia) e seu ritual de consagração, pois as operações técnicas do processo educativo não são técnicas, mas sociais, determinadas simbolicamente. Afirma que

O processo de transformação que se realiza nas escolas de elite é um rito de passagem que, por meio de operações mágicas de separação e de agregação [...], tende a produzir uma elite consagrada, quer dizer, não somente distinta, separada, mas também reconhecida e reconhecendo-se como digna de ser, em uma palavra, distinguida (Bourdieu, 1981, p. 30).

Os alunos já consagrados acabam sendo consagrados através dos efeitos da ação pedagógica anterior, responsável por inculcar-lhes as disposições necessárias para o ingresso e permanência na instituição. A nobreza escolar constitui-se em disposição imposta pelo grupo aos considerados nobres pelo grupo, e o pertencimento a essa esfera exclusiva autoriza tais pessoas a realizarem as obrigações que se espera que realizem, quase assumindo as características de um ato mágico.

A renhida competição no interior das Classes Preparatórias ou "a lógica do concurso permanente e do investimento permanente no concurso" (1981, p. 50), é considerada um dos deveres de tal nobreza. Os aspirantes às GE realizam investimento total nessa competição, sendo um exemplo da ideia de illusio. Para eles, esse jogo social vale a pena ser jogado, há sentido nos pesados investimentos de tempo e de energia dedicados aos estudos, no aceite absoluto dos conteúdos ensinados e nos métodos de ensino. Não há o reconhecimento do ato arbitrário presente em todo esse processo (nas provas, na ação pedagógica dos professores e nos concorrentes), isto é, nos valores que ancoram a concorrência e naquilo que se pretende obter: o título escolar. 
Em 1987 há dois números com o título Pouvoirs d'école 1 et 2 (Poderes da escola 1 e 2). No primeiro, Bourdieu e Monique de Saint Martin publicam "Agrégation et ségrégation: le champ des Grandes Écoles et le champ du pouvoir" (Agregação e segregação: o campo das Grandes Escolas e o campo do poder). No número seguinte ele escreve "Variants et invariants: éléments pour une histoire structurale du champ des Grandes Écoles" (Variantes e invariantes: elementos para uma história estrutural do campo das Grandes Escolas).

Em “Agrégation et ségrégation" constatam que artigos ou livros consagrados às GE geralmente derivam da relação socialmente instituída desta instituição: quanto mais a escola é legítima, maior será o número de monografias a ela dedicadas. Verificam que a maioria dos trabalhos aborda uma só escola, apreendendo-a em termos isolados, independentemente das relações objetivas que a une às outras GE e, de forma mais geral, às outras instituições de ensino superior. A posição atual ou potencial da escola estudada, avaliada a partir da hierarquia dos estabelecimentos, também parece ser o foco e o princípio da maioria dos discursos sobre tais estabelecimentos.

O escopo dos autores com o estudo que arrima o artigo é apreender a estrutura do campo das GE tomando como parâmetro instituições que pudessem ser representativas do universo observado. Descrevem a maneira como realizaram a pesquisa, explicando que através da aplicação de um questionário obtiveram indicadores objetivos das posições ocupadas nesse espaço, identificando, portanto, o campo e o subcampo das GE e demonstrando, ainda, a estrutura do campo das instituições escolares que contribuíam para assegurar tais posições.

Consideram um campo o universo dos estabelecimentos de ensino superior (Grandes ou Pequenas Escolas, Faculdades e Classes Preparatórias), sendo elemento estruturante o conjunto das relações objetivas entre os estabelecimentos ou entre os agentes que lhe são correspondentes. Esse campo se organiza segundo uma estrutura homóloga à do espaço social em seu conjunto, em que as GE ocupam o polo dominante e constituem, elas mesmas, um subcampo bem delimitado, cuja estrutura guarda relações de homologia com o campo do poder.

Para Bourdieu e Saint Martin, levando-se em consideração o conjunto das instituições pelo indicador origem social dos alunos ou o status das escolas (Pequenas ou Grandes), o campo dos estabelecimentos de ensino superior se diferencia por meio do acúmulo de prestígio social. O maior prestígio se percebe nas GE mais reconhecidas - a École Normale Supérieure (rua d'Ulm), a École Polytechnique e a École Nationale d'Administration -, que permitirão acesso às posições mais elevadas do espaço social. As pequenas instituições, gozando de menor prestígio, abonarão acesso às posições médias. $\mathrm{O}$ principal efeito social que emana do campo das instituições de ensino superior e do subcampo das GE tem seu princípio em uma 
dupla homologia estrutural: a homologia entre a oposição fundamental do campo, separando as Grandes das Pequenas Escolas ou das faculdades, constituindo assim um dos pontos mais estratégicos de todo o espaço social, uma fronteira contrastada e definitiva entre a grande burguesia e a pequena burguesia. $\mathrm{O}$ subcampo das $\mathrm{GE}$ se caracteriza também por outra homologia: pela oposição fundamental entre as escolas 'intelectuais' e as escolas do poder e a oposição que, no campo do poder, separa o polo intelectual ou artístico do polo do poder econômico ou político. Esse segundo efeito social ocorre com base naquilo que os autores denominam uma "verdadeira solidariedade orgânica", que consagra as identidades sociais, ao mesmo tempo concorrentes e complementares, porque solidárias, reunindo os alunos eleitos socialmente que asseguram a excelência do subcampo e produz um esprit de corps, denominado "grandes corpos" (1987, p. 18).

Com base nessa pesquisa percebem os mecanismos escolares como perpetuadores das diferenças constitutivas desse espaço social: nas GE existe a tendência da manutenção de tais diferenças baseada na estrutura do capital herdado entre alunos originários de distintas regióes do espaço social e do campo do poder. A origem social e o capital escolar entre as diferentes escolas como resultado de escolhas que se instauram na relação entre o habitus estruturado dos selecionadores dessas escolas e os selecionados, bem como a estrutura do campo das instituições escolares, são entendidos como responsáveis pela distribuição dos alunos em tal espaço (Bourdieu e Saint Martin, 1987, p. 18).

Após essas operações de seleção envolvendo as Classes Preparatórias e os concursos como ritos de instituição, são estabelecidas descontinuidades definitivas, fazendo com que, pelo arbitrário de uma fronteira social, o último selecionado seja separado, para sempre, do primeiro recusado. A consagração que assegura a obtenção da agregação em uma escola de prestígio tende a escotomizar nos agregados as inseguranças de sua história biográfica; o "ponto zero" ou inicial de sua trajetória irá determinar uma trajetória provável, compreendendo-se aí o desenho de uma carreira que não se situe tão distante desse "ponto zero" reconstruído - isso porque o título escolar garante um destino (social). No artigo citado identifica-se a aplicabilidade de outra noção central na sociologia de Bourdieu, a de campo, que se constitui em uma maneira de descrever as lutas concorrenciais travadas no espaço social selecionado e delimitado ${ }^{17}$. Em termos analíticos, campo é uma configuração de relações objetivas

17. Além de alguns textos que sistematizam a noção, como "Quelques propriétés des champs" (Bourdieu, 1980), ela é melhor compreendida nos seus livros - destaquem-se Les règles de l'art (1992), sobre a constituição do campo literário na segunda metade do século XIX e La noblesse d'État, que está sendo aqui debatido. Para uma discussão do campo acadêmico brasileiro, ver Hey (2008); sobre outras possibilidades analíticas dessa noção, ver Catani (2013). 
entre posições - posições essas estabelecidas em sua existência e nas determinações que impõem a seus ocupantes (agentes ou instituições) por sua situação atual e potencial na estrutura da distribuição de diferentes espécies de poder e de capital. Seu funcionamento é o mesmo de um campo magnético, capaz de impor aos objetos e aos agentes que nele penetram uma gravidade específica (1987, p. 16).

O outro artigo de Bourdieu, "Variants et invariants" (1987), inicia-se com questionamentos: qual é a validade, após vinte anos, de um estudo sobre o campo das GE realizado em 1967? Tal investigação valeria apenas como descrição histórica de um determinado momento ou não se revestiria de maior importância pelo fato de se apoiar em dados antigos? Para ele, os que consideram apenas o aspecto superficial do trabalho científico, reduzindo o sociólogo ou o historiador ao status de jornalistas levados a realizar discursos tão efêmeros quanto seus objetos de estudo, não demonstrariam interesse em tais abordagens (1987, p. 3). Com base em uma concepção oposta, o autor reforça esse gênero de pesquisa por servir de referência a outras mais recentes, pois

[...] é na condição de se ter em mente todas as transformações pelas quais passou a estrutura do campo das instituições de ensino superior - e do subcampo das Grandes Escolas de forma particular - que se podem interpretar de forma adequada fatos aparentemente tão simples como a representação, em distintas épocas, dos alunos oriundos de diferentes classes sociais em uma instituição determinada (1987, p. 3).

Para Bourdieu seria preciso abstrair, dos fatos mais gerais das experiências dos agentes, os fatos mais anedóticos, que poderiam acabar ocupando todo o campo de visão (os livros, os intelectuais da época, os filmes, as fotos antigas que mostram as roupas e os cortes de cabelo usados) impedindo, talvez, de se verificar a constância das estruturas profundas e as transformações que por acaso possam ter sofrido (1987, p. 4).É esse o problema proposto pelo sociólogo no texto. A pesquisa inicial realizada nos anos de 1960 passa a ser o parâmetro para identificar em que medida a estrutura do campo dos estabelecimentos de ensino superior se conservou ou se modificou - e, nesse caso, qual o sentido da transformação.

Examinando estatísticas do recrutamento social dos estudantes para 1984-1985e realizando comparações destes dados com os de bases análogas referentes ao período 1966-1970, é possível apreender a estrutura das instituições de educação superior na França. Com base nisso, Bourdieu afirma que a distribuição dos estabelecimentos de ensino superior apresenta uma estrutura global semelhante à do período anterior a 1968. O movimento soixante-huitard, ao invés de atingir um dos seus objetivos, qual seja, revolucionar as estruturas do campo das instituições de ensino superior, parece ter favorecido reações coletivas e individuais que as reforçaram. 
$\mathrm{Na}$ análise da distribuição das instituições de ensino superior, o primeiro fator distingue os estabelecimentos de acordo com o volume global de capital herdado (1987, p. 4). Alunos oriundos das classes dominantes estão presentes, majoritariamente, em algumas instituições (European Business School, École Supérieure de Sciences Économiques et Commerciales e École Nationale d'Administration), sendo minoritários nos Institutos Universitários de Tecnologia e nas Faculdades de Letras, reservados aos filhos de trabalhadores. Encontram-se no cume da hierarquia Grandes Escolas - a Polytechnique (engenharia e arquitetura) e a École Normale Supérieure, de Paris -, mas também outras menos exigentes academicamente, como as de comércio e de gestão.

Bourdieu demonstra o crescimento da École Nationale d'Administration nas disputas pelo recrutamento dos alunos que antes se dirigiam às GE, provocando fortes transformações no conjunto do campo. Ao mesmo tempo, apresenta o florescimento de novas instituições (escolas de gestão, marketing, publicidade, jornalismo) que atenderiam às estratégias dos filhos da burguesia de negócios que visam burlar o rigor da 'lei escolar' (1987, p. 8), pois não conseguiram ingressar nas GE e se recusaram a cursar pequenas escolas ou faculdades. São as chamadas "escolas refúgio" (1987, p. 19), exigindo dos que dependem da consagração escolar para a reprodução de suas posições sociais menor investimento escolar. O sucesso de tais escolas estaria associado ao desenvolvimento dessa nova demanda educacional, satisfazendo aos anseios dos jovens burgueses e de suas estratégias de reprodução social.

Destaca-se no artigo a exposição das “guerras palacianas” (ver Dezalay e Garth, 2002, para o uso da definição em outros contextos) na qual Bourdieu discorre acerca da necessidade de se conhecer as alterações no subcampo das GE, a fim de entender a reprodução do campo do poder. Assim, aponta as lutas de concorrência entre estas instituições, sendo que as mudanças na posição assumidas em relação à composição do campo do poder decorrem da estrutura das relações de força que se estabelecem entre si. As estratégias por elas engendradas para melhorar tal posição dependem do volume do capital específico - ao mesmo tempo social e escolar - de cada uma e da estrutura desse capital. Esse aspecto permite medir o peso do capital escolar, por meio da raridade das competências garantidas, e do capital social, relativo ao valor social atual ou potencial de seu público, tanto o de agora quanto o do passado $(1987$, p. 8). As guerras palacianas se travam em torno do acúmulo do capital simbólico das GE e de suas disposições para garantir privilégios e distinções àqueles por elas cooptados (socialmente), e apenas algumas escolas conseguem impor sua hegemonia em termos de suas posições relativas na hierarquia social e escolar - casos da École des Hautes Études Commerciales e da École Nationale d'Administration. 
Em 1992, nos números 91-92 do dossiê Politiques (Políticas), Bourdieu escreve dois artigos na sessão intitulada "La souffrance" (O sofrimento ${ }^{18}$ ): "Les exclus de l'intérieur" (Os excluídos do interior ${ }^{19}$ ), com Patrick Champagne, e "L'École et la cité" (A escola e a cité ${ }^{20}$ ). Ambos os trabalhos integrariam, em seguida, o livro que Bourdieu organiza La misère du monde (A miséria do mundo).

Em “Les exclus de l'intérieur”, os autores detectam uma sensação contínua de mal-estar quanto ao universo escolar. A partir dos anos de 1950 várias transformações afetaram o sistema de ensino:

[...] uma das que tiveram maiores consequências foi [...] a entrada no jogo escolar de categorias sociais que, até então, se consideravam ou estavam praticamente excluídas da escola, como os pequenos comerciantes, os artesãos, os agricultores e mesmo [...] os operários da indústria; processo que implicou uma intensificação da concorrência e um crescimento dos investimentos educativos por parte das categorias que já utilizavam, em grande escala, o sistema escolar (1992, p. 72).

Um dos efeitos mais paradoxais desse processo - definido de modo precipitado e estigmatizador como "democratização" - desvela-se, paulatinamente, para a "nova clientela" do sistema de ensino ("os mais despossuídos"), pela constatação de que apenas o ingresso no ensino secundário não era o bastante para se obter sucesso nele e, em especial, para alterar sua posição social com o término dos estudos ${ }^{21}$.

Por meio das pesquisas nos domínios das ciências sociais sobre a educação é possível perceber progressiva transformação no discurso dominante acerca da instituição escolar: o êxito ou o fracasso na escola deixam de ser atribuídos às deficiências pessoais dos excluídos ou à capacidade de superdotados dos “exitosos”. Assim, as reformas globais do sistema, reconhecidamente deficiente, envolvendo professores, currículos, sistemas de avaliação e políticas públicas em geral, preponderam em re-

18. Entre os números 90 e 93 publicaram-se vários artigos sob essa rubrica, com base em pesquisa sobre o sofrimento social daquelas pessoas que estão "mal dans leur peau", geradas pelo incômodo de sua posição social. Centrada na realização de mais de 150 entrevistas, origina a obra La misère du monde (1993). Essa enquete foi financiada pelo Programa de Desenvolvimento Solidariedade, da Caisse des Depôts et Consignations, da França.

19. Publicado em Nogueira e Catani (orgs.) (1998, pp. 217-228), e em La misère du monde; neste, porém, sem a entrevista que compunha o texto original.

20. Esse termo não tem tradução exata para o português; refere-se, no contexto, aos conjuntos habitacionais das periferias das grandes cidades.

21. O livro 80\% au bac et après? Les enfants de la démocratisation scolaire, de Stéphane Beaud (2002), ilustra esse desencantamento com a democratização escolar como categoria de promoção social aos jovens de classes populares. O estudo longitudinal (1991-2001) merece atenção pelo relato daqueles diretamente tocados pelas ilusões da mobilidade social via prolongamento da escolaridade. 
lação a talentos ou deficiências dos alunos. Em suma, "a lógica da responsabilidade coletiva tende [...] a suplantar, nas mentes, a lógica da responsabilidade individual, que leva a 'repreender a vítima”' (1992, p. 72).

O processo de eliminação dos alunos das classes desfavorecidas foi adiado e diluído, encontrando-se, na escola, "excluídos potenciais, vivendo as contradições e os conflitos associados a uma escolaridade sem outra finalidade que ela mesma" (1992, p. 72). A instituição escolar é vista "tanto pelas famílias como pelos próprios alunos, como um engodo e fonte de uma imensa decepção coletiva: uma espécie de terra prometida, sempre igual no horizonte, que recua à medida que nos aproximamos dela" (1992, p. 72). Assim, tal exclusão é ainda mais estigmatizante se comparada às exclusões do passado, pois, a rigor, tais alunos tiveram suas chances e não as aproveitaram.

O segundo texto, "L'école et la cité", traduzido como "Ah! Os belos dias", é ilustrativo da análise anterior, em que Bourdieu comenta a entrevista feita por ele e Rosine Christin com um filho de imigrante argelino de 19 anos. Detecta, no depoimento desse estudante, espécie de "teoria da economia das trocas escolares" (1992, p. 87), procurando ilustrar a forma de sobreviver na escola sem muito esforço. $\mathrm{O}$ objetivo dessa permanência seria tentar retardar a entrada na vida adulta, fugindo do temor do ingresso no mercado de trabalho - para esse estudante, possivelmente, o temor "da fábrica".

No número 105 da ARSS (1994), denominada Stratégies de reproduction et transmission despouvoirs (Estratégias de reprodução e transmissão dos poderes), há o texto de Bourdieu, "Stratégies de reproduction et modes de domination" (Estratégias de reprodução e modos de dominação ${ }^{22}$. Nesse estudo, escreve que uma das questões fundamentais a propósito do mundo social é saber por que e como tal mundo perdura e como a ordem é perpetuada, isto é, o conjunto de relações de ordem que constituem o mundo social (1994, p. 3). Insere, assim, a dominação nos processos complexos de reprodução social, afirmando que a sociedade se respalda na relação existente entre as disposições incorporadas nos indivíduos, a estrutura de distribuição do capital e os mecanismos que asseguram a reprodução. Esse arcabouço forja o sistema das estratégias de reprodução (educativas, econômicas, biológicas etc.) associado aos mecanismos de reprodução (sistema de ensino, mercado de trabalho,

22. Esse artigo dialoga com a quarta parte da obra La noblesse d'État e, ao lado de Les modes de domination (1976), retoma a sistematização da ideia de "modos de dominação", formulada pelo autor com base em seus estudos sobre a sociedade Cabila e de sua própria região, o Béarn, cuja interrogação centra-se nas maneiras de reprodução da vida social e nos mecanismos de dominação engendrados em estado prático na dinâmica das diferentes classes. Tal inquietação perpassa suas obras, desde os trabalhos iniciais, passando por La distinction e Sur l'État. 
direito de sucessão etc.), que variam nas distintas sociedades em função do tipo de capital que se quer transmitir e dos meios disponíveis para tal.

O modo de reprodução com componente escolar se funda na objetividade das estruturas sociais mediado pela organização do Estado, garantidor de um poder adquirido e vitalício, expresso no título escolar. Este abona uma competência objetivada e incorporada à qualidade individual, uma vez que ancorada no dom e no mérito, além de refletir disposições adquiridas no manejo da cultura legítima alinhadas pela submissão à lógica do sistema escolar. Assim, as estratégias educativas se caracterizam por serem de longo prazo, por produzirem agentes sociais capazes de receber a herança do grupo a que pertencem e por torná-los legítimos socialmente (1994, p. 5). A questão que se coloca é do uso diferencial da escola e da transmissão doméstica do capital cultural, desigualmente observado entre as classes.

No volume Inconscients d'école (Inconscientes de escola), de 2000, a apresentação do dossiê é um pequeno artigo de Bourdieu, de três páginas, com título similar. Ali argumenta que o inconsciente cultural ou transcendental histórico que funda o senso comum ou doxa constitui-se pelo sistema de esquemas cognitivos que estão no princípio da construção da realidade, e que são comuns ao conjunto de uma sociedade em dado momento (2000, p. 3). Assim, o inconsciente escolar é composto pelo conjunto das estruturas cognitivas incorporadas paulatinamente nas experiências propriamente escolares. Tais estruturas são partilhadas por todos os "produtos" de um mesmo sistema escolar, a todos que ensinam e cursam a mesma disciplina. $\mathrm{O}$ inconsciente escolar estabelece um arbitrário histórico que, incorporado - portanto naturalizado -, não permite que os agentes sociais dele tomem consciência. Destarte, a análise desse inconsciente necessita priorizar a relação pouco explorada "entre as estruturas institucionais (a história das disciplinas, por exemplo) e as estruturas cognitivas ou, de modo contundente, sua objetivação nos saberes e conhecimentos" (2000, p. 4).

\section{Considerações finais}

No período em que Bourdieu foi o editor de ARSS foram publicados 140 números e 31 deles contêm artigos relacionados à educação. Registre-se ainda que, entre 1975 e 1987, em 20 volumes foram detectados artigos na área, destacando-se os dossiês Le déclassement (n. 24, 1978), L'institution scolaire (n. 30, 1979), Grandes et Petites écoles (n. 39, 1981), Classements scolaires et classement social (n. 42, 1982), Éducation et philosophie (n. 47/48, 1983), Qu'est-ce que classer? (n. 50, 1983), Stratégies de reproduction 1 (n. 57/58, 1985) e Pouvoirs d'école 1 et 2 (n. 69 e 70, 1987). Após esse momento de maior concentração de dossiês e de produções sobre a educação, 
artigos isolados tornam-se mais recorrentes e apenas outros 2 dossiês aparecerão: Stratégies de reproduction et transmission des pouvoirs (n. 105, 1994) e Insconscients d'école (n. 135, 2000).

Nos onze textos escritos por Bourdieu verificam-se três períodos bem distintos. O primeiro refere-se aos artigos dos anos de 1970, em maior número, que reforçam a análise da constituição do capital cultural como recurso que contribui aos processos de reprodução social, uma vez que ele é desigualmente constituído e distribuído pelas diferentes classes e frações de classe. $\mathrm{O}$ sistema de ensino recebe o devido tratamento sociológico ao ser tomado como objeto, emergindo análises sobre as taxionomias escolares produzidas no seu interior e que atendem a princípios classificatórios dados socialmente, bem como a intensificação dos investimentos escolares visando à valorização dos diplomas. Nesses artigos constata-se, ainda, o interesse em explicitar como há um processo de interiorização dos sistemas classificatórios instituídos por meio do jogo social na aparência da naturalidade.

Dois artigos desse período, o primeiro e o terceiro, tratam especificamente dos diplomas, referindo-se explicitamente à lógica que permeia as mudanças na produção e no sistema de ensino. O segundo e o quarto relacionam-se pela exposição de como as estruturas sociais convertem-se em estruturas mentais, já anunciando problemática que seria desenvolvida em La noblesse d'État.

O segundo agrupamento aparece bem demarcado pelos três textos que vão compor La noblesse d'État. Publicados nos anos de 1980, retratam de forma densa a discussão em torno do processo de reprodução social pela exposição do campo das instituições de educação superior na França e do respectivo recrutamento social que impera nas escolas de elite, desde as classes preparatórias até as Grandes Escolas.

$\mathrm{O}$ último conjunto de artigos é composto pelos dois que integrarão a obra $\mathrm{La}$ misère du monde. Neles demarca-se o mal-estar do próprio autor em constatar que, apesar das alterações propaladas pela democratização escolar, o sistema de ensino nos anos de 1990 continua a atuar de diferentes maneiras nos processos denegados de reprodução social.

É nesse diálogo que "Stratégies de reproduction”, o outro artigo que compõe o conjunto vai tratar, de modo fulcral, da perpetuação da ordem social, costurando as indagações e as conclusões sobre a educação como um modo de dominação. Ao dialogar com exames anteriores das formas elementares de dominação em uma sociedade pré-capitalista (a sociedade Cabila), marcadas pela apropriação pessoal, direta, demonstra o que vai caracterizar um modo de dominação mais complexo. Tal processo se dá de forma a esconder a lógica social que institui a dominação, dissimulando-se por meio de relações encantadas para "ser reconhecida por meio do desconhecimento". Daí depreende que a análise dos mecanismos e das estratégias de 
reprodução, ou seja, de um lado as instituições escolares e de outro os investimentos educativos, engendrados segundo a posição da família no corpo social, permitem compreender a constituição do capital cultural e sua distribuição desigual. Assim as diferenças entre os modos de dominação repousam na existência de campos relativamente autônomos (o econômico, o cultural e o político), dotados de mecanismos próprios capazes de impor sua necessidade aos agentes. $O$ princípio de perpetuação da relação de dominação conta com instâncias como o Estado e a escola, por se constituírem em lugares de elaboração e de imposição de modos de dominação que se exercem até mesmo no universo das relações pessoais (Bourdieu, 1998).

Já o artigo de 2000 dialoga com "Sistemas de ensino, sistemas de pensamento" (1967) ao retomar a ideia de como os dispositivos acadêmicos estruturam formas cognitivas e em que medida há uma inculcação de sistemas classificatórios típicos do inconsciente escolar, logo arbitrários. A ênfase do artigo alerta para a necessidade do pesquisador objetivar o inconsciente cultural, esse conjunto de estruturas cognitivas que produzem categorias comuns de pensamento, de caráter nacional, comungadas por um conjunto de membros de uma mesma disciplina (científica).

Como se pode constatar ao longo da incursão pelos textos de Bourdieu referentes à educação, grande parte deles tratou dos aportes expostos em La noblesse d'État. Tal modelo analítico do campo das instituições de educação superior e a relação com a estrutura do campo do poder adquire o status de um programa de pesquisas a ser desenvolvido ultramar, testando os conceitos e as relações ali estabelecidas em contextos histórico-sociais peculiares. Além disso, reforça-se uma das frentes de investigação do autor em torno dos modos de dominação, constituídas pelo sistema escolar, pelo espaço social e o campo do poder e pela construção social da realidade (Pinto, 2000, p. 169).

Esse corpo de escritos permite situar a educação na produção sociológica de Bourdieu, mas, sobretudo, demarcar que a temática não constitui capítulo isolado de seu intento teórico, o de analisar a estrutura das relações que instituem objetivamente diferentes poderes, modos de dominação e estratégias de reprodução do mundo social. Buscamos dar uma noção de conjunto da obra do autor agregando textos específicos da ARSS às demais publicações, demonstrando como há um encadeamento das teses principais que motivaram a investigação daquilo que fundamenta sua Sociologia da Educação: a incorporação das estruturas sociais, isto é, dos sistemas classificatórios e a estruturação de sistemas de pensamento, de formas de agir e de pensar como motor da inserção dos seres em universos sociais constituídos e por eles constituintes. Isso corrobora nossa crítica à apropriação e vulgarização das teses centrais da educação do autor descolada da teoria sociológica que lhe dá corpo, comumente feita quando se tenta aplicar o autor no "campo educacional". 
Talvez como Simiand afirmou da produção pioneira de Durkheim em L'Année Sociologique, "l'espoir en serait justifié que la sociologie prît un jour son rang parmi les sciences" ([1898] 1987, p. 5) ${ }^{23}$, Bourdieu também realiza com a ARSS um manifesto pela sociologia acadêmica nos anos de 1970, elegendo objetos e desenvolvendo metodologias próprias para sua investigação. Inserindo-o no movimento da ciência contemporânea, pode-se afirmar que seu legado aí está: fornecer um olhar específico sobre o ordinário, desvelando o mais banal do instituído.

Artigos de Bourdieu sobre educação na revista ARSs (1975-2002)

- "Le titre et le poste: rapports entre le système de production et le système de reproduction”, n. 2, pp. 95-107, mar. 1975 (com Luc Boltanski).

- “Les catégories de l'entendement professoral”, n. 3, pp. 68-93, maio 1975 (com Monique de Saint Martin).

- "Classement, déclassement, reclassement", n. 24, pp. 2-22, nov. 1978.

- “Les trois états du capital culturel”, n. 30, pp. 3-6, nov. 1979.

- "Épreuve scolaire et consécration sociale: les classes préparatoires aux Grandes Écoles”, n. 39, pp. 3-70, set. 1981.

- "Agrégation et segregation: le champ des Grandes Écoles et le champ du pouvoir", n. 69, pp. 2-50, set. 1987 (com Monique de Saint Martin).

- "Variants et invariants: éléments pour une histoire structurale du champ des Grandes Écoles”, n. 70, pp. 3-30, nov. 1987.

- “Les exclus de l'intérieur”, n. 91/92, pp. 71-75, mar. 1992 (com Patrick Champagne).

- “L'école et la cité”, n. 91/92, pp. 86-96, mar. 1992.

- “Stratégies de reproduction et modes de domination”, n. 105, pp. 3-12, dez. 1994.

- “L'inconscient de l'école”, n. 135, pp. 3-5, dez. 2000.

23. "A esperança seria assim justificada se a sociologia um dia ocupasse seu lugar entre as ciências" (tradução nossa). A data entre colchetes refere-se à edição original da obra. 


\section{Referências Bibliográficas}

ARSS. (2004/2005), "Présentation: pour une Realpolitik de la recherche: au sujet de l'enquête du

CNRS sur les périodiques aidés par le département des sciences de l'homme et de la societé (sHS)". Paris, 155: 101-104, dec.

ARSS. (2006), Économies de la recherche (dossier). Paris, 164: 4-98, sept.

ARSS. (2009), "Présentation: pour une véritable politique en faveur des revues de SHS". Paris, 176/177: 145-147, mars.

BEAUD, Stéphane. (2002), 80\% au bac et après? Les enfants de la démocratisation scolaire. Paris, La Découverte.

Bourdieu, Pierre. (1974), A economia das trocas simbólicas (org. Sergio Miceli). São Paulo, Perspectiva.

Bourdieu, Pierre. (1975), "Présentation". Actes de la Recherche en Sciences Sociales, 1: 2-3, jan. Bourdieu, Pierre. (1976), "Les modes de domination”. Actes de la Recherche en Sciences Sociales, 2/3: 122-132, juin.

Bourdieu, Pierre. (1979), La distinction, critique sociale du jugement. Paris, Minuit.

Bourdieu, Pierre. (1980), “Quelques propriétés des champs”. In: Bourdieu, P. Questions de sociologie. Paris. Minuit, pp. 113-120.

Bourdieu, Pierre. (1982), “Leçon inaugurale (vendredi, 23 avril 1982)”. Chaire de Sociologie, Collège de France, Paris, (mimeo.).

Bourdieu, Pierrev. (1984), Homo academicus. Paris, Minuit.

Bourdieu, Pierre. (1989), La noblesse d'État: Grandes écoles et esprit de corps. Paris, Minuit.

Bourdieu, Pierre. (1992), Les règles de l'art: genèse et structure du champ littéraire. Paris, Seuil.

Bourdieu, Pierre (org.). (1993), La misère du monde. Paris, Seuil.

Bourdieu, Pierre. (1998), La domination masculine. Paris, Seuil.

Bourdieu, Pierre. (2000), “Chamadas". In: Bourdieu, P. O campo econômico: a dimensão simbólica da dominação. Org. Daniel Lins. Campinas, Papirus, pp. 17-34.

Bourdieu, Pierre. (2001), Meditaçôes pascalianas. Rio de Janeiro, Bertrand Brasil.

Bourdieu, Pierre. (2005), Esboģo de auto-análise. São Paulo, Companhia das Letras.

Bourdieu, Pierre. (2012), Sur l'État. Cours au Collège de France (1989-1992). Paris, Raisons d'Agir/Seuil.

Bourdieu, Pierre \& Delsaut, Yvette. (2005), "Entrevista de Pierre Bourdieu com Yvette Delsaut: sobre o espírito da pesquisa”. Tempo Social, 17 (1): 175-210, jun.

Bourdieu, Pierre (ed.) \& Miceli, Sergio (org.). (1997), Liber 1. São Paulo, Edusp.

Catani, Afrânio M. (2013), “As possibilidades analíticas da noção de campo social”. In: Catani, A. M. Origem e destino: pensando a sociologia reflexiva de Bourdieu. Campinas, Mercado de Letras, pp. 57-78.

DeZalay, Yves \& Garth, Bryant. (2002), La mondialisation des guerres de palais. Paris, Seuil. 
Ferenczi, Thomas. (2004), “Liber”. In: Hoog, E. et al. Pierre Bourdieu et les médias. Paris, L'Harmattan, pp. 59-68.

Grignon, Claude. (1975), "L'enseignement agricole et la domination symbolique de la paysannerie". Actes de la Recherche en Sciences Sociales, 1: 75-92, jan.

Hey, Ana Paula. (2008), Esboço de uma sociologia do campo acadêmico: a educação superior no Brasil. São Carlos, sP, Edufscar/Fapesp.

Karady, Victor. (1988), "Durkheim et les débuts de l'ethnologie universitaire”. Actes de la Recherche en Sciences Sociales, 74: 23-32, sept.

Medeiros, Cristina C. C. (2007), A teoria sociológica de Pierre Bourdieu na produção discente dos Programas de Pós-Graduação em Educação no Brasil (1965-2004). Curitiba, Tese de doutorado, Programa de Pós-graduação em Educação da Universidade Federal do Paraná.

Medeiros, Cristina C. C. (2013), "Educação em atos de pesquisa”. Cadernos de Educação, 44: 45-67, jan.-abr.

Miceli, Sergio. (2002), “Uma revolução simbólica”. Folha de S. Paulo, 27/jan, caderno 3-A.

Muel, Francine. (1975), "L'école obligatoire et l'invention de l'enfance anormale”. Actes de la Recherche en Sciences Sociales, 1: 60-74, jan.

Nogueira, Maria Alice \& Catani, Afrânio M. (orgs.). (1998), Pierre Bourdieu: escritos de educação. Petrópolis, Vozes.

PInto, Louis. (2000), Pierre Bourdieu e a teoria do mundo social. Rio de Janeiro, Editora FGV.

Poupeau, Franck. (2003), Une sociologie d'État: l'école et ses experts en France. Paris, Raisons d'Agir.

Simiand, François. (1987), "Pour une sociologie scientifique: la revue L’Année Sociologique de Durkheim”. In: Simiand, F. Méthode historique et sciences sociales. $1^{a}$ edição 1898. Paris, Éditions des Archives Contemporaines, pp. 1-5. Disponível em http://classiques.uqac.ca/ classiques/simiand_francois/methode/methode_07/socio_scientifique.pdf.

Wacquant, Loïc. (2002), "O legado sociológico de Pierre Bourdieu: duas dimensões e uma nota pessoal”. Revista de Sociologia e Politica, 19: 95-110, nov.

\section{Resumo}

A Sociologia da Educação de Bourdieu na revista Actes de la Recherche en Sciences Sociales O texto apresenta uma incursão pelos artigos sobre educação do sociólogo francês Pierre Bourdieu (1930-2002) publicados na revista Actes de la Recherche en Sciences Sociales (ARSS). Fundada por Bourdieu em 1975 e dirigida por ele até a sua morte, a ARSS acolheu onze de seus artigos na 
temática educacional (sendo quatro em co-autoria) entre 1975 e 2000. Ressalta-se que nas páginas do periódico o autor "rascunhou" vários trabalhos que viriam a se constituir em seus livros. Nos textos ali apresentados Bourdieu reafirma a relevância da sociologia da educação como um capítulo importante da sociologia do conhecimento e da sociologia do poder, fornecendo um verdadeiro programa de investigação para enxergar os mecanismos instituídos de produção da dominação e das estratégias de reprodução nas sociedades de classes contemporâneas.

Palavras-chave: Pierre Bourdieu; Actes de la Recherche en Sciences Sociales; Sociologia da educação; Educação, cultura e dominação; Educação e reprodução social.

\section{Abstract}

The sociology of education by Bourdieu in the Actes de la Recherche en Sciences Sociales

The sociology of education by Bourdieu in the journal Actes de la Recherche en Sciences Sociales The text presents an incursion in the articles by the french sociologist Pierre Bourdieu (19302002), published in the scientific journal Actes de la Recherche en Science Sociales (ARSS) having education as its subject. Created by Bourdieu in 1975 and directed by him until his death, ARSS received eleven of his articles (being four as co-writer) between the years of 1975 and 2000. Emphasising that in the pages of the periodical the author "drafted" several papers that would become his books. In these presented texts Bourdieu reafirms the relevance of the sociology of education as an important chapter of the sociology of knowledge and the sociology of power, granting a real programme of investigation to unfold the instituted mechanisms in the production of the domination and the strategies of reproduction in the contemporary society class. Keywords: Pierre Bourdieu; Actes de la Recherche en Sciences Sociales; Sociology of education; Education, culture and domination; Education and social reproduction.

Texto recebido em 28/10/2016 e aprovado em 17/10/2017.

DOI: $10.11606 / 0103-2070 . t s .2018 .122400$

ANA PAUla HEY é professora no Departamento de Sociologia da USP e uma das organizadoras do Vocabulário Bourdieu (Autêntica, 2017).E-mail: anahey@usp.br.

AFRÂNio MENDES CaTANi é professor na Faculdade de Educação da USP. Pesquisador do CNPq, é um dos organizadores do Vocabulário Bourdieu (Autêntica, 2017).E-mail: amcatani@usp.br. CRISTINA CARTA CARDOSO DE MEDEIRos é professora no Departamento de Educação Física da UFPR e uma das organizadoras do Vocabulário Bourdieu (Autêntica, 2017).E-mail: crisccm@ ufpr.br. 